\title{
No sentido da vida. Em diálogo sobre a prevenção do suicídio
}

\author{
Maria Teresa de Freitas Cardoso
}

\section{Resumo}

Na perspectiva do diálogo sobre a prevenção do suicídio, acolhemos resultados da ciência e refletimos sobre possibilidades de contribuição católica no sentido da vida. Propomos considerações teológicas e pastorais e reportamo-nos a motivos bíblicos. A fé cristã contempla a vida humana como dom sagrado. Todas as pessoas são chamadas por Deus a uma comunhão de amor e a vida é um dom fundamental, aberto à eternidade. A Igreja ensina 0 Evangelho na direção da vida e do amor. O quinto mandamento conduz ao respeito da vida. O comportamento suicida não deveria acontecer. Pesquisas científicas mostram que na maior parte das vezes se poderia atestar que o suicídio está relacionado com distúrbios mentais e elas advertem que ele poderia ser prevenido. A pessoa em risco deve ser protegida e ajudada. A Igreja pode contribuir na valorização da vida, na sua proteção e na sua realização mais plena. Ela é chamada a atuar com amor, em sua espiritualidade, seus ensinamentos, sua solicitude pastoral e no apoio a várias formas de ajuda, dentre elas a da assistencia médica. A cura e o serviço da vida e a prevenção do suicídio são temas para diálogo com a ciência e com as outras religiões.

Palavras-chave: Vida, Prevenção, Suicídio, Amor 


\begin{abstract}
In the perspective of the dialogue about prevention of suicide, we consider scientific findings and we reflect on possibilities of Catholic contribution to the meaning of life. We propose theological and pastoral considerations and refer to biblical principles. Christian faith contemplates human life as a sacred gift. All persons are called by God to a communion of love, and life is a fundamental gift, open to eternity. The Church teaches the Gospel for guidance of life and of love. The fifth commandment conveys respect for life. Suicidal behavior should not happen. Scientific research demonstrates that, in most cases, suicide can be proven to be related to mental disorders and calls attention to the fact that it can be prevented. The person at risk needs to be protected and helped. The Church may contribute in the valuing of life, in its protection and fullest realization. It is called to act with love, through its spirituality, teachings, pastoral solicitude and support for various forms of help, among which is medical assistance. Healing, the service of life and prevention of suicide are themes for dialogue with science and with other religions.
\end{abstract}

Keywords: Life, Prevention, Suicide, Love

\title{
Introdução
}

A vida humana é contemplada pela fé cristã como um dom sagrado e o serviço da vida decorre do próprio evangelho, que se entende como evangelho da vida. A pessoa é chamada a uma vida em plenitude. O direcionamento para a plenitude envolve muitos aspectos do viver. No entanto, a peregrinação desta vida pode se deparar com muitas dificuldades para o pleno desenvolvimento da pessoa, inclusive enfermidades e ameaças ao simples viver. Quando a vida está em risco, importa protegê-la.

Um dos aspectos da valorização e da proteção da vida e uma questão sobre a qual hoje se investiga é a prevenção do suicídio. ${ }^{1}$ A orientação contra o suicídio

\footnotetext{
${ }^{1}$ A Organização Mundial da Saúde (OMS) define suicídio como o ato de deliberadamente se matar. Os fatores de risco incluem transtornos mentais e algumas enfermidades. Entretanto, existem medidas que podem prevenir o suicídio. "Suicide is the act of deliberately killing oneself. Risk factors for suicide include mental disorder (such as depression, personality disorder, alcohol dependence, or schizophrenia), and some physical illnesses, such as neurological disorders, cancer, and HIV infection. There are effective strategies and interventions for the prevention of suicide", Cf. WORLD HEALTH ORGANIZATION, Health topics. Disponível em $<$ http://www.who $>$. Acesso em 12 de abril de 2011.).
} 
se inclui na teologia moral e na pastoral católica, embora sem lugar mais destacado. ${ }^{2}$ Tendo em vista, porém, que o problema aumentou em nossos tempos, este artigo pretende colaborar com uma visão positiva da vida e uma atitude preventiva. Procuramos refletir sobre a contribuição que a fé, o convívio eclesial e a ação pastoral poderiam dar em diálogo com a ciência e com os serviços especializados.

Trataremos primeiro da prevenção do suicídio levando em conta alguns resultados de pesquisas científicas. Depois refletiremos teologicamente sobre a sacralidade da vida humana e a vocação para a comunhão do amor de Deus, entrevendo alguns aspectos do sentido da vida e de valorização de seu cuidado. Abordaremos a prevenção do suicídio relacionada com o quinto mandamento. Finalmente trataremos do potencial de contribuição da Igreja na prevenção do suicídio, de sentido e de realização. Concluiremos com a consideração de tudo isso para o diálogo e a colaboração.

\section{Em busca da prevenção}

Não se costuma fazer nos meios católicos uma pastoral específica contra o suicídio, e há motivos para isso, pois não se vê aí o objeto direto da fé e da vida cristã. A orientação está antes voltada positivamente para a vida, seu cuidado, sua cura. São abundantes as referências sobre a vida e sobre a defesa da vida, bem como são incontáveis os serviços da caridade, muitos deles para auxiliar pessoas em meio a carências, enfermidades ou dificuldades.

Por outro lado, ao menos em parte, parece que se justifica a falta de abordagem direta do suicídio pelo temor de com isso despertar ou aumentar o problema, ou seja, o temor de levar os fiéis a um perigoso envolvimento com o tema, de um modo que aumentassem os riscos. Não se deseja uma tentativa de prevenção com uma palavra ou uma ação mal orientadas, que talvez levassem ao contrário do seu propósito.

Existe razão em se ter prudência pastoral, pois é preciso falar adequadamente. Seria, porém, equivocado optar pelo silêncio sempre e faltar com uma atuação naqueles momentos em que caberia falar francamente e dar uma orientação necessária. O que acontece muitas vezes é o desconhecimento

\footnotetext{
${ }^{2}$ Pesquisa sobre o suicídio na literatura religiosa no Brasil constata maior produção de textos entre os kardecistas, com destaque para a prevenção. Observou-se que a literatura católica que aborda essa temática tem sido escassa. Cf. ESTELLITA-LINS, C. - BTESHE, M. - OLIVEIRA, V. M. - CLÉBICAR, T. SALLES, I, "Suicídio na literatura religiosa: o kardecismo como fonte bibliográfica privilegiada", RECIIS - R. Eletr. de Com. Inf. Inov. Saúde 3 (2010) pp. 37-50. Disponível em <http://www.reciis.cict.fiocruz.br> acesso em 13 de abril de 2011.
} 
tanto do risco real quanto dos meios de prevenção. Parece que a ignorância também poderia levar a um julgamento errôneo sobre uma pessoa que incorre em risco de se suicidar ou que de fato já tentou o suicídio. É importante considerar e tratar adequadamente essas pessoas e suas famílias.

Desse modo, a partir de uma proclamação do sentido da vida e ao mesmo tempo em que se impõe a prudência pastoral, torna-se também importante aprender a prevenir e, para isso, a falar desse tema de modo adequado, posto que o silêncio nem sempre é a melhor opção. É importante ter uma reflexão teológica que contemple o sentido da vida. É bom experimentar o sentido da vida. É também útil encontrar elementos que favoreçam o viver. Para a reflexão teológico-pastoral e para a orientação prática, temos na fé cristã uma luz do evangelho como evangelho da vida e descobrimos na prática cristã possibilidades de serviço da vida, particularmente pelo amor e a caridade. Diante de problemas graves como o do risco de suicídio, existem estudos específicos da parte das ciências, sob vários aspectos, com observações também de caráter humano ou social, e eles muitas vezes poderiam auxiliar a prática cristã e a pastoral da Igreja. Interessa ficar aberto a um diálogo.

As pesquisas científicas investigam não só causas e estatísticas de suicídio, mas sobretudo as possibilidades da prevenção. Identificam as populações e os fatores de maior risco e apontam também aqueles outros fatores que protegem mais as pessoas. Entre os fatores protetores contaríamos: "ter acesso a tratamentos, contar com apoio social, cultivar vínculos afetivos, sentir-se integrado num grupo ou comunidade; seguir alguma religião ou crer na espiritualidade". ${ }^{3}$ Reconhece-se que "a fé e a prática religiosa parecem exercer uma influência positiva". ${ }^{4}$

As pesquisas confirmam que o suicídio decorre, na quase totalidade dos casos, de distúrbios ou "transtornos" mentais. A Associação Brasileira de Psiquiatria faz ver que "uma revisão de 31 artigos científicos publicados

\footnotetext{
${ }^{3}$ Cf. ESTELLITA-LINS, C. et alii, op. cit., p. 39. Os autores citam N. J.BOTEGA, N. J. et alii: "pessoas com maior envolvimento religioso de um modo geral possuem menores taxas de suicídios". ESTELLITALINS et alii fazem ver que o apoio social de grupos religiosos auxilia, mas que influenciam também os contextos culturais: "A disponibilidade de um sistema de crenças que proporciona sentido à vida e ao sofrimento, as regras referentes a estilos de vida saudável (proibição de abuso de álcool e uso de drogas) e, sobretudo, o apoio social dos grupos religiosos são mecanismos auxiliares na resolução ou na adesão ao tratamento. É notório, contudo, que diferentes valores culturais têm ascendência sobre esses índices. Isto porque as formas de religiosidade se desenvolvem dentro de contextos específicos, podendo atuar ora como fator protetor ora como vulnerabilizante".

${ }^{4}$ Conforme comunicação oral, em 8 de abril de 2011, do Grupo de Pesquisa de Prevenção do Suicídio do ICICT/FIOCRUZ (Rio de Janeiro, Brasil), coordenado pelo Prof. Dr Carlos Eduardo Estellita-Lins.
} 
entre 1959 e 2001, englobando 15.629 suicídios na população geral, demonstrou que em mais de $90 \%$ dos casos caberia um diagnóstico de transtorno mental à época do ato fatal". ${ }^{5} \mathrm{O}$ suicídio muitas vezes está ligado a um transtorno depressivo, que entretanto pode ser tratado. ${ }^{6}$ Além disso, as populações em maior risco são de dependentes do álcool e da droga. Muitas vezes são de jovens sob conflitos intensos ou encontrando-se em situações novas que não podem suportar ou idosos sob o peso da sua condição. Costumam ser pessoas que ficam psiquicamente enfermas e que precisavam de uma ajuda específica. Pelo menos em larga escala, parece que o suicídio pode ser visto como um problema de saúde pública que pode ser prevenido.? Para atender a essa necessidade da sanidade mental e ao cuidado da vida, existem as responsabilidades das áreas médica e de política da saúde. Entretanto, também outras pessoas na sociedade podem ajudar: escutar uma intenção ou perceber o agravamento de sinais depressivos e "orientar a pessoa ou sua família a procurar um serviço de saúde especializado". Deve-se saber também que "não fazer julgamentos é muito importante". ${ }^{8}$ As pesquisas ensinam ainda como abordar o assunto de modo adequado, pois às vezes falar, se falar corretamente, é prevenir. ${ }^{9}$

Também a Igreja tem a sua contribuição. Não se trata de pretender substituir o serviço médico ou de outros setores de atendimento. Ela realiza

\footnotetext{
${ }^{5}$ Cf. ASSOCIAÇÃO BRASILEIRA DE PSIQUIATRIA, Comportamento suicida: conhecer para prevenir - dirigido para profissionais da Imprensa, ABP Editora, Rio de Janeiro, 2009, p. 16. A orientação sobre como abordar o suicídio na imprensa visa a mostrar como informar colaborando para prevenir.

${ }^{6} \mathrm{O}$ suicídio está relacionado entre as possíveis conseqüências e os riscos da depressão. Cf. T. C. TUNG e F. N. DEMÉTRIO, Manual informativo sobre transtorno depressivo, Programa Educacional GRUDA Ambulim do Instituto de Psiquiatria das Clínicas da Faculdade de Psiquiatria do Hospital da Faculdade de Medicina da Universidade de São Paulo, São Paulo, s.d., p. 14. Também o Grupo de Pesquisa de Prevenção do Suicídio do ICICT/FIOCRUZ apontou para nós a relação com a depressão, com uma estimativa aproximada de que seriam $40 \%$ os casos de depressão, $25 \%$ seriam de dependência química de álcool ou drogas psicoativas; $20 \%$ de transtornos da personalidade; $10 \%$ de esquizofrenia, e apenas uma parcela pequena se refiriria a casos com conotação política ou filosófica. Conforme comunicação oral referida na nota 4. O mesmo grupo de pesquisa acentua que se podem tomar medidas preventivas.

${ }^{7}$ A Associação Brasileira de Psiquiatria considera que "em nosso país, até há pouco tempo, o suicídio não era visto como um problema de saúde pública". Recentemente o Ministério da Saúde montou um grupo de trabalho com a finalidade de elaborar um Plano Nacional de Prevenção do Suicídio. Entre os seus principais objetivos está o de "informar e sensibilizar a sociedade de que o suicídio é um problema de saúde pública que pode ser prevenido". Cf. ASSOCIAÇÃO BRASILEIRA DE PSIQUIATRIA, Op. cit., p. 19.

${ }^{8}$ Conforme comunicação oral do Grupo de Pesquisa de Prevenção do Suicídio do ICICT/FIOCRUZ.

${ }^{9}$ Para se falar adequadamente, recomenda-se relacionar o suicídio com transtornos mentais e enfatizar que existem tratamentos. Algumas outras recomendações seriam: não detalhar métodos, sua letalidade, não tomar o suicídio consumado como se fosse um ato de coragem, não dizer "bem sucedido", não mostrar cartas de despedida nem fotografias. Conforme comunicação oral do Grupo de Pesquisa de Prevenção do Suicídio do ICICT/FIOCRUZ. Ver também as orientações do manual da Organização Mundial da Saúde: Prevenção do suicídio. Um recurso para conselheiros. Disponível em $<\mathrm{http}: / / \mathrm{www}$.who.int $/$ mental_health/ media/counsellors_portuguese.pdf>. Acesso em 21 de setembro de 2010.
} 
sua própria vocação de fé e vida. Atua com opção pelas pessoas em sua caridade e em sua missão de anúncio evangélico e na comunicacão de vida espiritual. Isso pode ser um fator positivo de proteção ou prevenção. A Igreja pode e deve dialogar e colaborar. A questão que estudamos demanda uma interdisciplinaridade e uma intercolaboração.

\section{A sacralidade e o sentido da vida}

A Igreja proclama o valor sagrado da vida. A vida é um dom primeiro e fundamental. Para a fé cristã, a vida humana é realidade preciosa e sagrada, seja por seu caráter de dom primeiro e fundamental, insubstituível, seja pela sua destinação de eternidade.

É natural querer viver, querer viver mais, querer viver melhor. O ser humano está voltado para uma plenitude de vida. É vocacionado para a vida eterna. Para participar da vida divina. Para ser feliz na comunhão do Amor.

A vida terrena é relativa à destinação última da vida eterna. Toda ela é revestida de um valor primeiro e sagrado e a sua vocação sobreeleva ainda o seu valor. A pessoa deve poder percorrer essa peregrinação desde o começo até o termo natural, quando fará a passagem para a condição plena da vida eterna. $\mathrm{O}$ dom da vida é único. A pessoa é chamada pelo Amor e para o Amor. Espera-se a vida eterna e de certo modo ela já se pode iniciar. Pode-se dizer que a sacralidade da vida com sua busca de plenitude e sua vocação de amor constituem um embasamento valioso para se proteger a vida e ajudar a viver. João Paulo II se refere à sacralidade da vida em sua Encíclica Evangelium vitae. ${ }^{10}$

A dignidade humana se descreve na linguagem teológica católica com o conceito de imagem de Deus. A imagem de Deus não somente é uma

\footnotetext{
${ }^{10}$ JOÃO PAULO II discorre sobre o tema da sacralidade da vida em sua Encíclica "Evangelium vitae" (1995), na qual trata de alguns pontos de bioética. Inicia a carta afirmando que "o evangelho da vida está no centro da mensagem de Jesus" (n. 1). Fala do caráter sagrado da vida na relação com sua destinação de plenitude: "O homem é chamado a uma plenitude de vida que se estende muito para além das dimensões da sua existência terrena, porque consiste na participação da própria vida de Deus" (n. 2). Insiste na sublimidade da vida e na relação com essa destinação: "A sublimidade desta vocação sobrenatural revela a grandeza e o valor precioso da vida humana, inclusive já na sua fase temporal. Com efeito, a vida temporal é condição basilar, momento inicial e parte integrante do processo global e unitário da existência humana: um processo que, para além de toda a expectativa e merecimento, fica iluminado pela promessa e renovado pelo dom da vida divina, que alcançará a sua plena realização na eternidade (cf. 1Jo 3, 1-2). Ao mesmo tempo, porém, o próprio chamamento sobrenatural sublinha a relatividade da vida terrena do homem e da mulher. Na verdade, esta vida não é realidade 'última', mas 'penúltima'; trata-se, em todo o caso, de uma realidade sagrada que nos é confiada para a guardarmos com sentido de responsabilidade e levarmos à perfeição no amor pelo dom de nós mesmos a Deus e aos irmãos" (n. 2).
} 
representação de Deus e de sua soberania, mas também é chamada a viver segundo Deus, a participar da sua comunhão amorosa. A sublime vocação humana é o Amor. Cada pessoa é chamada pelo Criador a viver para encontrar o amor: ser amada e amar. Ou seja, para receber o amor e responder no amor. É o que Bento XVI ensina em sua Encíclica Deus caritas est,${ }^{11}$ vendo também no amor o caminho de vida da Igreja e encontrando a sua fonte no próprio Deus, que se define, conforme Jo 4, 8, Deus mesmo, como Amor.

Cada pessoa deve ser acolhida e inserida na comunhão do amor, que dá sentido à vida. A oração de Jesus, diante da Hora, é uma oração na intenção de que todos vivam na unidade perfeita e no amor, de modo que esteja em nós o seu amor, o amor do Pai em Jesus como Jesus está no Pai (cf. Jo 17). Na participação dessa vida divina, em comunhão do Amor, realiza-se o dom pedido por Jesus na unidade de todos se manifesta o Evangelho a ser acreditado. Jesus viveu e morreu para entregar o Espírito e, com o Espírito, comunicar vida e comunhão. A vida eterna desejada (os discípulos ficam com Jesus porque Ele tem palavras de vida eterna, cf. Jo 6,68 ) é vida de comunhão (cf. 1Jo 1,3-4).

O sofrimento, nunca totalmente compreendido, e que deve ser quanto possível aliviado e superado, é também percebido na fé junto com a busca de um sentido maior e uma esperança final que o ultrapasse. Pode ser caminho de aprendizado, de amadurecimento, de intercessão e de redenção, e nesses aspectos se integra num sentido maior de vida. Experimenta-se o sofrimento, muitas vezes, como inevitável e por vezes se procura uma possibilidade de sua frutificação. Entretanto, enquanto peso, limite, dor, enfermidade, o sofrimento é uma diminuição da plenitude de vida e deve ser eliminado e superado, pois é o serviço da vida que deve prevalecer, sanando-a ao máximo, e aliviando-a de toda dor. $\mathrm{O}$ amor o exige. Em Cristo vemos um amor que se entrega totalmente, que inclusive passa pelo sofrimento, integrando tudo na doação do amor e proporcionando uma redenção que comunica vida em plenitude. Permanece um mistério e ao mesmo tempo irradia uma luz na fé a redenção cristã, que, assim por amor, embora passe pela cruz de Cristo, orienta para a esperança da vitória desse amor e a comunicação da plenitude da vida.

No seguimento de Cristo, o discípulo está no caminho do Mestre e este caminho é o do amor. O cristão encontra em Cristo uma motivação para amar a todos e para socorrer e aliviar a quem sofre. É uma exigência do

${ }^{11}$ Para BENTO XVI, na sua Encíclica "Deus Caritas est", "o amor nasce como resposta ao amor de Deus (n. 17) É preciso ter recebido primeiro o amor (n. 7). 
evangelho, atender a quem precisa. Pelo evangelho de Cristo se acredita na ressurreição, dom de vida plenificada, motivo de esperança. O sofrimento, que não podemos compreender totalmente, e que se deve procurar aliviar, na fé é associado ao sofrimento redentor de Cristo. A fé motiva o discípulo a buscar a graça e a vida eterna e, a exemplo de Cristo, a proporcionar o bem a todos; assim, a cuidar do enfermo ou do que sofre, como expressão de amor. ${ }^{12}$

Desse modo, a vida humana já neste mundo tem um significado transcendente pela relação com Deus e pelo encaminhamento para a plenitude. Ela é entendida como um dom de Deus e um direito da pessoa. É dom e direito fundamentais. A fé consagra o valor natural da vida.

Na prevenção do suicídio, trata-se de procurar ajudar a si próprio ou de ajudar o outro a viver. Muitas vezes isso se faz concretamente redimensionando-se o entendimento da própria vida, reconduzindo-se seus caminhos, abrindo-se perspectivas. Muitas vezes precisa-se de meios que aliviem as dores trazidas pelas enfermidades ou as calamidades, ou de integração que diminua a situação de isolamento social. Portanto, muitas vezes se depende de uma ação efetiva e afetiva, que integre a pessoa na experiência do amor - ser amado, amar, caminhar para a comunhão definitiva do amor de Deus - vocação para a qual toda pessoa foi criada. Essa experiência pode acontecer, dependendo muitas vezes de providências no nível material ou espiritual, psicológico, familiar, eclesial, social. A vida é sagrada, mas se vê que é frágil, necessitando de proteção e de ajuda. Se a vida humana tem um chamamento para a comunhão amorosa, é na inserção comunitária e na relação interpessoal, nos laços, na partilha, nos cuidados, na medicina, e certamente em um modo de viver acolhedor e oblativo, que a vida encontra sua melhor possibilidade de realização.

No contexto do sentido, a conduta da própria vida se deve pautar pelo amor, que é um valor fundamental e o motivo da Lei. No caso da prevenção do suicídio, proteger a vida em risco e ajudar ao que precisa de ajuda para viver são modos de honrar o Criador e de concretizar o amor ao próximo como a si mesmo. Muitos são os textos bíblicos que apontam para a vida. A Bíblia

\footnotetext{
${ }^{12}$ A exortação de Bento XVI Verbum Domini (2010), escrita para que na Igreja se renove a escuta da Palavra do Senhor e nela se viva, preocupa-se com "todos aqueles que estão em condições de sofrimento físico, psíquico ou espiritual". Defende que é "a vida humana digna de ser vivida plenamente, mesmo quando está debilitada pelo mal". Lembra aos cristãos que "a proximidade de Jesus aos doentes não se interrompeu", mas continua "na missão da Igreja", na ação dos "homens de boa vontade" e "nas atividades de assistência". As pessoas doentes deveriam também ser ajudadas a "descobrir que podem [...] participar de um modo particular no sofrimento redentor de Cristo" (n. 106).
} 
no seu conjunto é certamente uma palavra de vida. Indiquemos mais algumas referências bíblicas na direção da vida, do seu aprendizado ou do seu cuidado.

Reportamo-nos à Lei da aliança, no Antigo Testamento. O contexto da Lei dada por Deus é de libertação, de salvação. O povo experimentara o êxodo. É um povo liberto. A Lei é o caminho da vida, de viver como povo de Deus, um povo libertado. A Lei se resume no amor a Deus e ao próximo. O povo aprende na Lei o caminho da vida. ${ }^{13} \mathrm{O}$ livro do Deuteronômio exorta a acolher as leis de Deus para garantir a vida. Ou seja, a finalidade da palavra dada por Deus ou do ensinamento que foi dado pela mediação de Moisés é a vida. O povo é chamado a viver. Diz o livro do Deuteronômio: "Ouve os estatutos e as normas que eu hoje vos ensino a praticar, a fim de que vivais" (Dt 5,1).

Também o Novo Testamento relaciona os mandamentos com a vida. Respondendo à pergunta sobre o maior mandamento (Mt 22, 36-40), Jesus refere o maior mandamento, do amor a Deus (que está em Dt 6, 5); em seguida, aproxima deste mandamento o mandamento do amor ao próximo (que está em Lv 19, 18.34), acrescentando que de ambos dependem a Lei e os Profetas. No relato lucano (Lc 10, 25-28) a pergunta se coloca a propósito da vida eterna e Jesus, tendo apresentado os dois mandamentos, conclui: "faze isto e viverás" (v. 28). A orientação da prática cristã sintetizada no amor a Deus e ao próximo é a vida eterna. A própria vinda de Jesus se apresenta no quarto evangelho como um dom copioso de vida. Destaquemos a seguinte afirmação de Jesus: "Eu vim para que tenham a vida e a tenham em abundância” (Jo 10, 10).

$\mathrm{O}$ evangelho se orienta para o dom da vida eterna, com a comunhão divina, ${ }^{14}$ mas podemos reconhecer que fica valorizada já esta própria vida, onde, aliás, o dom da vida eterna já começa a comunicar-se. Justifica-se, de acordo com o evangelho da vida, toda proteção e todo serviço de ajuda à vida humana, tudo aquilo que, no amor, possa ajudar a pessoa a viver e a realizar-se o mais plenamente possível. Com efeito, Jesus proporcionava o bem às pessoas, já nesta vida, como sinal de amor, de libertação e do dom pleno da vida. A sua passagem na terra foi descrita no livro dos Atos dos Apóstolos: "ele passou fazendo o bem e curando a todos os que estavam dominados pelo diabo" (At 10, 38). Nos evangelhos sinóticos, a pregação de Jesus foi acompanhada de

\footnotetext{
${ }^{13} \mathrm{O}$ rabino P. H. PELI, falando do aprendizado da Torá, chama a atenção de que o verbo é ensinar, que "os estatutos e decretos não devem ser impostos, mas ensinados [...] eles nos ensinam o modo de viver Cf. P. H. PELI, “A coragem de estudar. A Torá hoje”, La Vie Spirituelle 733 (1000) pp. 576-579.

${ }^{14}$ Os temas da Vida, do amor e da comunhão se interpenetram. Cf. Jo 17, 26; 1Jo 1, 1-4; 3, 23-24.
} 
sinais do Reino - de evangelizar os pobres, de libertar, de consolar, de curar. No evangelho joaneu se diz que Jesus "amou até o fim" (Jo 13, 1). Assim podemos dizer que toda a vida de Jesus até a sua entrega final se resume em amar e fazer o bem, as pessoas são amadas e curadas, e isso é sinal do Reino dos céus e é consoante com o dom da vida em abundância, para a eternidade.

\section{A prevenção do suicídio em relação com o quinto mandamento}

A Igreja orienta os fiéis a viverem de acordo com a fé e os mandamentos. O quinto mandamento, que proíbe matar - "não matarás" (cf. Ex 20, 13) - aponta para a vida. Achamos fundamental reconhecer que estão no espírito do mandamento a dignidade da vida e o cuidado que lhe corresponde. Seriam valores aí implicados: os de respeitar a vida, preservá-la, guardá-la, protegê-la, salvá-la, curá-la, servi-la, ajudá-la. O motivo disso tudo é o amor pela pessoa, pois o mandamento que está na base de todos os mandamentos é o do amor.

Existe na Igreja o cuidado de levar em conta a moralidade das ações. ${ }^{15}$ Procura-se uma boa formação da consciência e deseja-se respeitar o sentido da liberdade e da responsabilidade. ${ }^{16}$ Ensinam-se os mandamentos, que norteiam o agir, visando ao bem, na aliança com Deus. ${ }^{17} \mathrm{O}$ comportamento suicida, que contradiz a inclinação natural à vida, é interpretado como uma ação contra o quinto mandamento. Ao ensinar isso, a catequese toma uma direção preventiva.

Não se pode, porém, fazer o julgamento das pessoas. Nem cabe a nós julgar a interioridade das pessoas ou o seu destino final. Para a visão cristã, só Deus é o Juiz (cf. Tg 4, 12). A atitude de não julgar as pessoas torna-se importante no que diz respeito à prevenção do suicído, dado que "uma recomendação médica" é que "não devemos julgar uma pessoa com histórico de suicído: não ajudaria na prevenção". 18

A propósito, devemos considerar que a pesquisa científica concluiu que se poderia atestar na grande maioria dos casos de suicídio tratar-se de distúrbio mental. Nesse contexto, a reflexão e o arbítrio, para a atuação plenamente livre da

\footnotetext{
${ }^{15}$ JOÃO PAULO II ensina que "a moralidade do ato humano depende primária e fundamentalmente do objeto razoavelmente escolhido pela vontade deliberada". Cf. Encíclica "Veritatis splendor", n. 78.

${ }^{16}$ Cf. Catecismo da Igreja Católica, sobre liberdade e responsabilidade, nn. 1731-1748; sobre a consciência moral e a formação da consciência, nn. 1776-1785.

${ }^{17}$ Ver o decálogo em contexto de aliança: Ex 19; 24. Cf. Catecismo da Igreja Católica, 2060-2061.

${ }^{18}$ Conforme comunicação oral do Grupo de Pesquisa de Prevenção do Suicídio do ICICT/FIOCRUZ.
} 
vontade, podem ficar abalados. Pode haver circunstâncias de enfermidade mental ou de grave sofrimento ou medo. Ou de problemas graves com álcool ou droga. Tudo isso faz pensar sobre a complexidade das situações, o que pode reforçar a atitude de não julgar as pessoas. Importa, sim, respeitar a pessoa e prevenir o mal, cercar de cuidados quem está em risco e quem já atentou contra a própria vida. Assim o exigem a dignidade da pessoa, o valor da vida e o mandamento de respeitá-la. Também a família dessas pessoas merece respeito, apoio e oração.

Houve uma evolução no modo de a legislação na Igreja tratar o assunto e buscar a prevenção. Anteriormente, havia sanções para a pessoa sobre a qual se pudesse afirmar que causara a própria morte de maneira deliberada ("deliberato consilio"), implicando-se, para a sanção, que houvesse comprovação disso (não se podia simplesmente presumir). Então, no caso em que se comprovasse um suicídio consumado de modo deliberado, deixando-se o juízo da pessoa sempre para Deus, podiam ser feitas orações e também a aplicação, em caráter particular, da missa, mas se proibia o ritual das exéquias e a missa solene. A oração e a missa aplicadas em caráter particular não tem menos valor que a solene. A sanção, porém, visava mostrar a reprovação da ação, ou o repúdio. ${ }^{19}$ Pode-se pensar que havia nisso uma intenção preventiva: fazer que as outras pessoas não cometessem o suicído.

No atual Código de Direito Canônico (1983) os cânones sobre a privação das exéquias eclesiásticas e da missa exequial não relacionam os que causam a própria morte. ${ }^{20}$ Isso não significa deixar a orientação cristã para a vida e para a prevenção. Parece, no entanto, que se leva melhor em conta a complexidade do problema.

\footnotetext{
${ }^{19}$ Dom Estêvão Bettencourt comenta essas medidas. Fizera-se à sua revista a seguinte pergunta: "Não se sabendo o que se passou no último instante entre a alma e Deus, por que nega a Igreja assistência religiosa (enterro, Missa solene, etc) aos suicidas?". Na resposta, Dom Estêvão BETTENCOURT se reportava à legislação de então (vigorava o antigo Codex Iuris Canonici, de 1917): “A legislação da Igreja, no assunto, se pode circunscrever aos seguintes termos: a) visa apenas aqueles que recorrem 'de maneira deliberada, deliberato consilio' (cf. can. 1240 \& 1 n. 3)." Dom Estêvão explicava ainda: a aplicação da sanção não se faria para os casos em que as pessoas "já não são responsáveis por seus atos", ou quando "conste que o suicídio não foi premeditado nem voluntário". Dom Estêvão acrescentava que, se houve sinais de retratação, arrependimento ou penitência, seria "preciso tornar notório, a fim de evitar o escândalo público". Explicitava que isso tinha em vista "unicamente os suicidas reconhecidos como tais", não se podendo presumir o suicídio sem comprovação da deliberação. De qualquer forma "a Igreja de modo nenhum atribui a condenação eterna", pois o destino eterno só é conhecido por Deus, mas a sanção se fazia porque a ação deveria ser "denunciada e repudiada". Seria ainda permitida "a aplicação do S. Sacrifício em caráter particular", sabendo-se que seus frutos não dependem da solenidade externa. Cf. Pergunte e Responderemos 5 (1957) pp. 24-25.

${ }^{20}$ Cf. Código de Direito Canônico - Codex Iuris Canonici, promulgado por João Paulo II, Papa, trad. Oficial: Conferência Nacional dos Bispos do Brasil, São Paulo: Edições Loyola, 1983, cân.1184-1185.
} 
O Concílio Vaticano II, na Constituição “Gaudium et Spes” (1965), sobre a Igreja no mundo de hoje, ao tratar do respeito para com a pessoa humana, "inculca o respeito" a todo ser humano. O concílio considera a "imperiosa obrigação de nos tornarmos próximos de qualquer homem indistintamente". $\mathrm{O}$ documento se refere a "tudo o que atenta contra a própria vida", e nisso inclui “o suicídio voluntário". ${ }^{21}$ A já mencionada encíclica "Evangelium Vitae” (1995), de João Paulo II, retoma o texto da GS, inclusive citando o "suicídio voluntário" entre as ameaças à vida humana como ameaças que hoje tomam novo vulto. É, sem dúvida, intuito desses textos advertir contra o "suicídio voluntário" e levar ao respeito e à proteção da vida humana, que tem um valor sagrado.

No Catecismo da Igreja Católica (1992) o suicídio é contraposto ao quinto mandamento. Considera-se a reponsabilidade pela vida e o dever de preservá-la e que o suicídio contradiz a inclinação natural por conservar a vida. Ele é visto como uma ação que ofende o amor a si, o amor aos outros e o amor a Deus. O Catecismo acrescenta que adquiriria ainda a gravidade do escândalo se fosse cometido com a intenção de servir de exemplo e que a cooperação voluntária ao suicídio é contrária à lei moral. Observa-se, porém, que determinadas circunstâncias podem diminuir a responsabilidade: como distúrbios psíquicos, angústia, medo grave, sofrimento, tortura. Declara-se que a Igreja ora pelas pessoas que atentaram contra a própria vida. Observammos aqui que não as exclui, portanto, do seu amor. ${ }^{22}$

Ressaltamos dois princípios presentes nessas ponderações do Catecismo: o do dom da vida a preservar e o do amor que se deve ter. Achamos que o empenho em orientar o fiel para a vida e para o amor é um modo de buscar a prevenção.

A Igreja é chamada a responder a Deus, viver o amor e cumprir sua missão. Para isso deve ensinar o evangelho e praticar os mandamentos. Parece-nos que a prevenção do suicídio está implicada no espírito do quinto mandamento. No nosso entender, junto com o respeito e a opção pela vida se devem ter todos os cuidados para com as pessoas - especialmente as que estão em risco -, de modo que sejam respeitadas, protegidas e ajudadas no seu viver.

\section{Aspectos de contribuição por parte da Igreja}

A Igreja pode contribuir para a prevenção do suicídio de modo direto

${ }^{21}$ Cf. CONCÍlIO VATICANO II, Constituição pastoral “Gaudium et Spes”, n. 27.

${ }^{22}$ Cf. Catecismo da Igreja Católica, nn. 2280-2283. 
e de modo indireto. Como atuação direta, contaríamos ações no sentido de ajudar a pessoa em risco a optar pela vida, a buscar nova perspectiva de vida ou renovação da vida, a ter o auxílio material ou psicológico que está sendo necessário. Como sua atuação indireta, mas que consideramos fundamental, pensamos em tudo aquilo que, no âmbito eclesial, pode favorecer a vida, o sentido da vida, as possibilidades de viver, a responsabilidade pelo viver, a realização de uma vida humana e comunitária mais salutar e mais feliz.

A Igreja contribui certamente no exercício de sua missão e sua caridade e dentro de sua própria vida: pela evangelização, pela prática espiritual e litúrgica e por várias formas de ajuda. Vejamos dois modos de contribuição que poderiam se dar dentro da Igreja.

\subsection{Uma ajuda que considera o serviço profissional da saúde}

Uma ajuda fundamental no campo de prevenção do suicídio é a valorização do serviço próprio dos profissionais da saúde. Também a pastoral da saúde pode ser atuante, como pastoral. No atendimento às pessoas aparece um campo de interdisciplinaridade e de cooperação. Cabe abrir espaço para a troca de conhecimentos e de apoio, bem como de ajuda prática no que cada um pode oferecer. Existe o que pode e deve ser feito na Igreja - da parte de clérigos e fiéis enquanto tais - e o que deveria ser feito pelos setores competentes da área médica, da área política, e demais segmentos da sociedade. Cada qual colabora em sua perspectiva e atuação própria, sem tentar substituir um ao outro. São complementares. Devem todos visar ao bem da pessoa.

Obervamos que uma contribuição é ajudar a pessoa que mostra sinais de depressão, de grande sofrimento ou outro sinal de risco, ou por parecer necessitar de atendimento psicológico e médico, a buscar um atendimento profissional, se parecer isso conveniente. Às vezes uma palavra basta.

Existem comunidades paroquiais que apóiam e favorecem o serviço voluntário de profissionais para os mais carentes. Existem alguns esforços de diálogo entre a fé e a psicologia. Existem serviços de apoio humano na solidariedade e fraternidade. Há pessoas que procuram na Igreja assistência espiritual ou o encontro com outras pessoas - e devem receber isso -, mas também buscam ou precisam de um auxílio específico para atender a sua condição. E pode-se encontrar na Igreja apoio a projetos de suporte para pessoas que poderiam incorrer diretamente no risco do suicídio, como dependentes de 
droga e álcool ou pessoas marcadas por uma história dolorosa na qual se sintam incapacitadas de lidar com problemas graves ou em casos de problemas do sentimento de culpa. ${ }^{23}$

Como o risco de suicídio pode se contar entre as ameaças de nosso tempo, deve-se estar atento para ajudar as pessoas em risco a receberem o devido atendimento preventivo. Muitas dessas pessoas não têm ideia do caminho a tomar. Sofrem. Não é raro que venham a tentar amparo e auxílio na Igreja. Ali é o lugar em que muitas vezes os problemas aparecem. Por um lado, já é uma ajuda direta o acolhimento eclesial mostrando a solicitude pastoral e a solidariedade dos membros da comunidade - isso é necessário. Sublinhamos que não se deve descuidar do auxílio espiritual. Por outro lado, no entanto, a assistência profissional pode ser também necessária e por isso deve ser valorizada. A palavra adequada muitas vezes é falar na possibilidade de tratamento.

\subsection{A contribuição pelo serviço espiritual e pela própria vida eclesial}

Uma outra forma de contribuição que a Igreja Católica pode dar está no exercício da sua missão e na realização de sua própria vida. Compreendem-se aqui a evangelização e a proposta de sentido, o culto que relaciona com Deus e conduz para a esperança, o alimento espiritual e toda caridade, os laços de comunhão e as várias formas de fazer o bem. Incluir na comunhão faz bem ao outro que é incluído e faz bem a quem promove essa inclusão.

De acordo com o que apontamos na primeira parte desse trabalho, existem fatores que ajudam a viver. Contamos aqui, entre os elementos que ajudam na realização pessoal e na saúde mental: ser aceito como pessoa, estar inserido em uma comunidade, ter um sentido da vida, encontrar alívio no sofrimento, capacidade de lidar com as dificuldades, achar uma resposta para os limites da existência e a sede de infinito, realizar o desejo de ser amado e de amar. Muitas vezes os laços humanos e comunitários e o socorro ou o auxílio que se prestam às pessoas são de grande valia para criar condições salutares de vida mental. Do mesmo modo, são importantes tanto o esclarecimento das pessoas sobre os cuidados com sua vida como todo serviço de cura das pessoas - cura corporal, cura psíquica, cura espiritual. Tudo isso ajuda a viver.

Destacamos cinco pontos nos quais poderíamos contar com a

\footnotetext{
${ }^{23}$ Como exemplos, poderíamos referir aqui a Fazenda da Esperança e a pastoral da sobriedade para apoiar pessoas com dependência. Ou o Projeto Esperança, para capacitação do apoio a mulheres com síndrome pós-aborto.
} 
contribuição na Igreja no serviço da vida, porque realiza dimensões importantes para se poder viver bem e pode ajudar a seus fiéis e de algum modo contribuir na sociedade. A Igreja pode proporcionar:

1) Sentir-se acolhido, pertencer à comunidade. Contaríamos aqui o exercício do acolhimento e a inserção na comunidade eclesial; a pertença à comunidade e os laços interpessoais. Poderia ser de grande contribuição o cuidado com os ministérios de acolhimento. Também os movimentos, círculos, associações, festas comunitárias, feiras beneficentes, e diversas formas de participação e serviço ajudam a viver o dado da pertença e realizam a inserção, e dão lugar ao florescimento e ao compartilhamento dos próprios dons. Isso ajuda a pessoa a realizar-se mais.

2) Encontrar um sentido de viver e valores dignos de abraçar. As religiões possuem uma visão da vida e um sentido de vida. Também a fé cristã contribui com um sentido de vida. Oferece uma razão para viver e apóia valores dignos de abraçar. No meio das dificuldades, das decepções, dos fracassos e dos pecados, a fé pode ajudar a redimensionar a vida. A ter perspectivas. A reconduzir-se. A realizar obras que signifiquem esse sentido e dêem o sentimento de estar contribuindo. Ter valores dignos ajuda a pessoa a elevar-se para o melhor, a optar, a empenhar-se. Saber que contribui, ajuda a reconfortar-se. Encontrar um sentido, ajuda a alegrar-se e a ser feliz.

3) Melhor lidar com o problema do sofrimento. Embora não possa solucionar totalmente o problema do sofrimento, a Igreja ajuda a promover o auxílio ao que sofre para que este seja aliviado tanto quanto possível, de tal modo que o sofrimento seja, se possível, ultrapassado. Também procura integrar o sofrimento na fé, em relação com a redenção de Cristo, de tal modo que, ao passo que tenta diminuir as dores humanas, ainda espera a vitória final sobre todo sofrimento. Além das obras chamadas de obras de misericórdia, pelas quais se atende aos que sofrem, cabe aqui valorizar toda a contribuição dos ministérios de esperança e de consolação.

4) "Encontrar Deus". A Igreja pode ajudar a "encontrar Deus". Propõe uma experiência religiosa. Considera a abertura humana de transcendência. Ajuda a suportar os limites dessa vida, os sentimentos de vazio, de dúvida, de impotência, de insuficiência com a perspectiva do infinito. Favorece a humildade diante do mistério. Pode ajudar a descobrir uma presença do divino na interioridade de cada um, particularmente na experiência do amor, e a encontrar a paz. O aprendizado da oração e o ato sagrado da liturgia podem ajudar a redimensionar a vida. A religião pode servir de suporte. 
5) Ser amado, amar. Uma experiência de capital importância, que é também a de ser inserido numa comunhão: a de ser amado; a de aprender a amar. Junto disso, pela motivação cristã são feitas as "obras de misericórdia". Ou seja, coloca-se o coração junto ao que sofre. Seria a ajuda às pessoas que estão em situação de sofrimento ou de fragilidade ou de necessidade. Isso é importante para quem contribui com o dom de si e de suas obras, pois realiza um sentido de vida no seu gesto de amor. Ser amado e amar, é salutar. Torna feliz. Para quem é ajudado, muitas vezes é a ajuda de que necessitava. $\mathrm{Na}$ Igreja apóiam-se diversos serviços e projetos de promoção do bem.

Consideramos que tudo isso ajuda a viver. Ajuda a fazer prosseguir a própria vida, ajuda o outro a prosseguir na dele. Todos esses elementos que tratamos nessa seção mostram um potencial da fé e da prática cristã no contexto da vida eclesial, quando bem conduzida, para ajudar a viver.

\subsection{Dois pontos particulares}

Temos visto um grande potencial de contribuições dentro da vida da Igreja. Entretanto, parece oportuno ressaltar dois pontos particulares: o primeiro é que mesmo algumas pessoas da comunidade eclesial, talvez atuantes, podem em algum momento precisar de ajuda; o segundo é que se espera da Igreja uma atitude de aproximação.

1) As pessoas podem precisar de ajuda. Não basta se ter escutado o Evangelho ou se freqüentar a Igreja Católica ou conviver com pessoas que proclamem todo um sentido de vida, para se estar a salvo de experiências de solidão, de dor, de tropeço, de insucesso, de depressão, de conflitos, de dependências, de ser vítima de violência, de ter medos, de não querer mais viver. Essas são dificuldades que, às vezes, a pessoa não sabe administrar ou não tem condições de administrar sozinha. Mesmo pessoas de fé e mesmo pessoas consagradas por votos religiosos podem necessitar de um auxílio mais específico. Pessoas da Igreja ou que se aproximam da Igreja, as que vivem em seus meios ou que convivem com elas na sociedade podem sofrer muito por esses problemas. Muitas pessoas trazem traumas desde a infância. Muitas sofreram impactos quando jovens ou adultos, ou estão sob o peso da idade avançada.

Observou-se um potencial de contribuição de fé e de vida interior, também de apoio ou promoção de auxílios humanos. A missão evangelizadora anuncia um sentido de viver mais pleno. Entretanto, ainda que seja verdadeiro 
que a Igreja tem um grande potencial de valorização da pessoa, de promoção humana e de ajuda a viver, deve-se cuidar na Igreja de não se perder o bem que ela pode dar. Ou seja, embora sempre aconteçam certas limitações humanas, requerem-se a vigilância e o cuidado para se evitar o que causa maior sofrimento ou desorientação, às vezes traumas, ou o que contradiz o respeito e o acolhimento da pessoa e da plenitude de vida que a Igreja quer promover.

2) Solidariedade e consolo, diálogo e interdisciplinaridade. Poderia ser sublinhada a contribuição na Igreja com um plano pastoral marcado pela "conversão pessoal" e a "conversão pastoral", no seguimento de Cristo e atento à necessidade dos tempos, na linha do CELAM em Aparecida. ${ }^{24}$ Os bispos da América Latina reportaram-se às palavras de Bento XVI no início de seu pontificado, quando o papa retomava o espírito da Constituição pastoral Gaudium et Spes, do Vaticano II. O papa disse: "A Igreja, que participa dos gozos e esperanças, das tristezas e alegrias de seus filhos, quer caminhar a seu lado neste período de tantos desafios, para infundir-lhes sempre esperança e consolo". ${ }^{25}$ Uma presença e um acompanhamento, uma mensagem e uma orientação, um serviço, uma troca, uma palavra ao coração, podem constituir precioso auxílio. A referência ao Mistério, aparentemente pouco interessante para o mundo secularizado, pode tornar-se entretanto importante para pessoas inquietas e insatisfeitas com respostas imediatas mas muito limitadas, típicas de nosso mundo. Mesmo que não se vejam de imediato os frutos, a solicitude eclesial pode ser fator de fé, de esperança, de amor - e de vida.

Também são importantes o diálogo e a interdisciplinaridade. Importa uma espiritualidade que ajude a renovar a própria vida, também a fazer prosseguir. $\mathrm{O}$ atendimento profissional pode ajudar. O diálogo é útil. Por exemplo, entre fé e psicologia, fazendo valer um verdadeiro sentido de contrição sem se deixar levar a um sentimento doentio de culpa. Buscar uma renovação de vida, uma reparação, uma correção de rumo, um renovado empenho sem se confundir uma boa disposição com um estado de ansiedade. Viver dentro do quadro positivo e salutar de humildade verdadeira, de purificação, de aprendizado e de avanço. Descobrir o verdadeiro sentido do perdão e da reconciliação, como aprofundamento do dom de si e como restauração ou

${ }^{24}$ CONSELHO EPISCOPAL LATINO-AMERICANO, Documento de Aparecida. Texto conclusivo da V Conferência Geral do Episcopado Latino-Americano e do Caribe, Brasília: Edições CNBB, Paulus Paulinas, São Paulo, 2007, nn. 366-368.

${ }^{25}$ Cf. idem, n. 16. Trata-se da homilia de Bento XVI no solene início do seu ministério petrino, aos 24 de abril de 2005 . 
crescimento da comunhão. Isso pode ajudar a encontrar possibilidades e perspectivas. A espiritualidade aprende e por sua vez contribui.

Religião não é isolamento e hoje a vida é tema de discussão na sociedade. A religião pode motivar as pessoas a abrirem-se ao encontro dos outros e também a solidarizarem-se na defesa da vida e na busca de qualidade de vida. Busca-se uma ação responsável e conjunta. Torna-se importante o diálogo entre pessoas de diferentes religiões e com pessoas sem religião, respeitando-se as crenças e as consciências. A contribuição pode ser de todos. E a solicitude é para com toda pessoa.

\section{Conclusão}

A vida é um dom fundamental e sagrado, que deve ser protegido. $\mathrm{Na}$ fé cristã o sentido da vida humana relaciona-se com um chamado divino e uma destinação eterna para a comunhão do amor de Deus. Ser amado e amar constituem a principal realização da pessoa. É essa a direção para o aprendizado da vida. Além disso, o valor da vida e a busca de sua plenitude motivam a cuidar da pessoa, a procurar sua cura, a fazer todo o bem. Isso é requerido pelo amor, que é o fundamento de todos os mandamentos.

$\mathrm{Na}$ catequese católica se ensina que o comportamento suicida se opõe ao dom da vida e é uma ação contra o quinto mandamento. O Catecismo, porém, faz ver também que a responsabilidade da pessoa pode estar diminuída por causa de circunstâncias como situações de distúrbios psíquicos, grave sofrimento ou medo. Pesquisas atuais sobre suicídios atestam que eles quase todos estão relacionados com transtornos mentais. Além disso, a ciência hoje mostra ainda que existem caminhos de prevenção. Esta muitas vezes se dá por um atendimento adequado e uma de suas recomendações é não julgar a pessoa que tentou suicidar-se. É interessante que se tem observado entre os fatores protetores da vida a inserção comunitária, os laços, a religião.

Parece-nos que na Igreja muito se pode contribuir para a prevenção do suicídio. Pode-se atuar com o anúncio evangélico e a orientação moral no sentido da vida e do amor. Pode-se colaborar diretamente na prevenção conduzindo a buscar o serviço da saúde e apoiando as obras de assistência. Já um modo indireto, mas importante, de contribuir está no que se proporciona de positivo no convívio eclesial, favorecendo a vida: o acolhimento da pessoa e a inserção na comunidade, a comunicação de sentido e de valores, o serviço espiritual, os 
gestos de amor e de consolação e ajudas diversas na cura e na caridade. Também uma atitude de aproximação e certos cuidados pastorais podem ser valiosos.

Assim como a vida é tema de interesse ecumênico e universal, também a prevenção do suicídio pode se beneficiar de diálogo, de interdisciplinaridade e de colaboração. Trata-se de contemplar o sentido da vida e de promover a sua proteção e o seu cuidado para que se viva e se viva do melhor modo.

\section{Referências Bibliográficas}

ASSOCIAÇÃO BRASILEIRA DE PSIQUIATRIA, Comportamento suicida: conhecer para prevenir - dirigido para profissionais da Imprensa, ABP Editora, Rio de Janeiro, 2009.

BENTO XVI, Carta Encíclica "Deus Caritas Est” (2005), Paulus - Loyola, São Paulo, 2006.

Paulinas, São Paulo, 2010.

BETTENCOURT, E., Pergunte e Responderemos 5 (1957) pp. 24-25.

Bíblia de Jerusalém, Paulus, São Paulo, 2002.

Catecismo da Igreja Católica, Vozes, Petrópolis - Paulinas - Loyola - AveMaria, São Paulo, 1993.

Código de Direito Canônico - Codex Iuris Canonici, promulgado por João Paulo II, Papa, trad. oficial: Conferência Nacional dos Bispos do Brasil, Notas e comentário: Jesus Hortal, S.J., Loyola, São Paulo, 1983.

CONCÍLIO VATICANO II, Constituição pastoral "Gaudium et Spes” (1965), in Compêndio do Vaticano II. Constituições. Decretos. Declarações, Vozes, Petrópolis, 1991.

CONSELHO EPISCOPAL LATINO-AMERICANO, Documento de Aparecida. Texto conclusivo da V Conferência Geral do Episcopado Latino-Americano e do Caribe (2007), Edições CNBB, Brasília - Paulus - Paulinas, São Paulo, 2007.

ESTELLITA-LINS, C. - BTESHE, M. - OLIVEIRA, V. M. - CLÉBICAR, T. -SALLES, I, Suicídio na literatura religiosa: o kardecismo como fonte bibliográfica privilegiada, in RECIIS - R. Eletr. de Com. Inf. Inov. Saúde, Rio de Janeiro, 3 (2010) pp. 37-50.

JOÃO PAULO II, Encíclica "Evangelium vitae" (1995), in SARTORI, L. M. A. (org), Encíclicas do Papa João Paulo II. O profeta do ano 2000, Editora LTr, 1996, São Paulo, pp. 537-616. 
-_-_-, Encíclica "Veritatis splendor" (1993), in SARTORI, L. M. A. (org), Encíclicas do Papa João Paulo II. O profeta do ano 2000, Editora LTr, 1996, São Paulo, pp. 459-532.

ORGANIZAÇÃO MUNDIAL DA SAÚDE, Prevenção do suicídio. Um recurso para conselheiros. Disponível em $<\mathrm{http} / / / \mathrm{www} . w h o>$

PELI, P. H., "A coragem de estudar. A Torá hoje", La Vie Spirituelle 733 (2000) pp. 576-579.

TUNG, T. C. - DEMÉTRIO, F. N., Manual informativo sobre transtorno depressivo, Programa Educacional GRUDA - Ambulim do Instituto de Psiquiatria das Clínicas da Faculdade de Psiquiatria do Hospital da Faculdade de Medicina da Universidade de São Paulo, São Paulo, s.d.

WORLD HEALTH ORGANIZATION, Health topics. Disponível em $<$ http:// www.who>

Maria Teresa de Freitas Cardoso

Doutora em Teologia pela PUC-Rio

Professora na PUC-Rio

Professora na Faculdade de São Bento do Rio de Janeiro

Artigo Recebido em 09/06/2011

Artigo Aprovado em 01/08/2011 